\title{
A rare case of mixed germ cell tumor in a teenage girl: a case report
}

\author{
Faraz S. Vali*, Amit Kyal, Parul I. Chaudhary, Sujatha Das, \\ Aprateem Mukherjee, Partha Mukhopadhyay
}

Department of Obstetrics and Gynecology, Medical College and Hospital, Kolkata, West Bengal, India

Received: 03 April 2017

Accepted: 02 May 2017

\author{
*Correspondence: \\ Dr. Faraz S. Vali, \\ E-mail: farazvali@gmail.com
}

Copyright: (C) the author(s), publisher and licensee Medip Academy. This is an open-access article distributed under the terms of the Creative Commons Attribution Non-Commercial License, which permits unrestricted non-commercial use, distribution, and reproduction in any medium, provided the original work is properly cited.

\begin{abstract}
Germ cell tumors represent only $20 \%$ to $25 \%$ of all benign and malignant ovarian neoplasms. Mixed germ cell tumors are a rare variety of non-dysgerminomatous germ cell tumors. They contain two or more elements; the most frequent combination being a dysgerminoma and an EST (Endodermal Sinus Tumor). We present a case of malignant mixed germ cell tumor comprising of yolk sac tumor, embryonal carcinoma and choriocarcinoma. A 13-year-old girl presented with a huge $25 \times 18 \mathrm{~cm}$ mass in abdomen with raised values of CA-125, hCG, AFP (alpha-feto protein) and $\mathrm{LDH}$ (lactate dehydrogenase). She underwent laparotomy followed by unilateral salpingoopherectomy and infracolic omentectomy. Histopathology report revealed malignant mixed germ cell tumor comprising predominantly of EST with elements of embryonal carcinoma and non-gestational choriocarcinoma. Following surgery, she was started on adjuvant chemotherapy (Bleomycin, Etoposide and Cisplatin regimen). Mixed germ cell tumor (YST/EST, nongestational choriocarcinoma and embryonal carcinoma) is a very rare tumor. Careful initial surgery with adequate staging biopsies followed by combination chemotherapy can greatly improve the prognosis of these patients.
\end{abstract}

Keywords: Embryonal cancer, Mixed germ cell tumor, Non-gestational choriocarcinoma, Yolk sac tumor/endodermal sinus tumor

\section{INTRODUCTION}

Germ cell tumors originate from the primitive germ cells. They represent up to $15 \%$ of ovarian cancers in Asian and African American societies. In the first two decades of life, almost $70 \%$ of ovarian tumors are of germ cell origin, and one-third of these are malignant. Mixed germ cell malignancies of the ovary are rare variety of nondysgerminomatous germ cell tumors. They contain two or more elements.

The most common component is dysgerminoma, which occurred in $80 \%$, followed by EST in $70 \%$, immature teratoma in $53 \%$, choriocarcinoma in $20 \%$, and embryonal carcinoma in $16 \%$. The most frequent combination is a dysgerminoma and an EST. The mixed lesions may secrete either AFP, hCG, or both or neither of these markers, depending on the components. We present a case of malignant mixed germ cell tumor comprising of yolk sac tumor, embryonal carcinoma and non-gestational choriocarcinoma. Rare combination of uncommon germ cell components, huge size, intact capsule, very high levels of tumor markers makes this case unusual and therefore, we report this case.

\section{CASE REPORT}

A 13-year-old girl presented with chief complain of swelling and pain in lower abdomen for 30 days. Swelling and pain increased rapidly in 30 days and was associated with nausea, loss of appetite, weight loss and abdominal distension. Patient had achieved menarche just 6 months back and had regular menstruation. There was no family history of tuberculosis, ovarian, breast, colon 
carcinoma, etc. Her vitals were as follows: pulse 76/min, blood pressure- 110/70 $\mathrm{mmHg}$, weight - $52 \mathrm{~kg}$, mild pallor, no edema or lymphadenopathy. Bilateral breath sounds were normal and other systemic examination was within normal limits. Tanner stage of breast and pubic hair were stage 3 each.

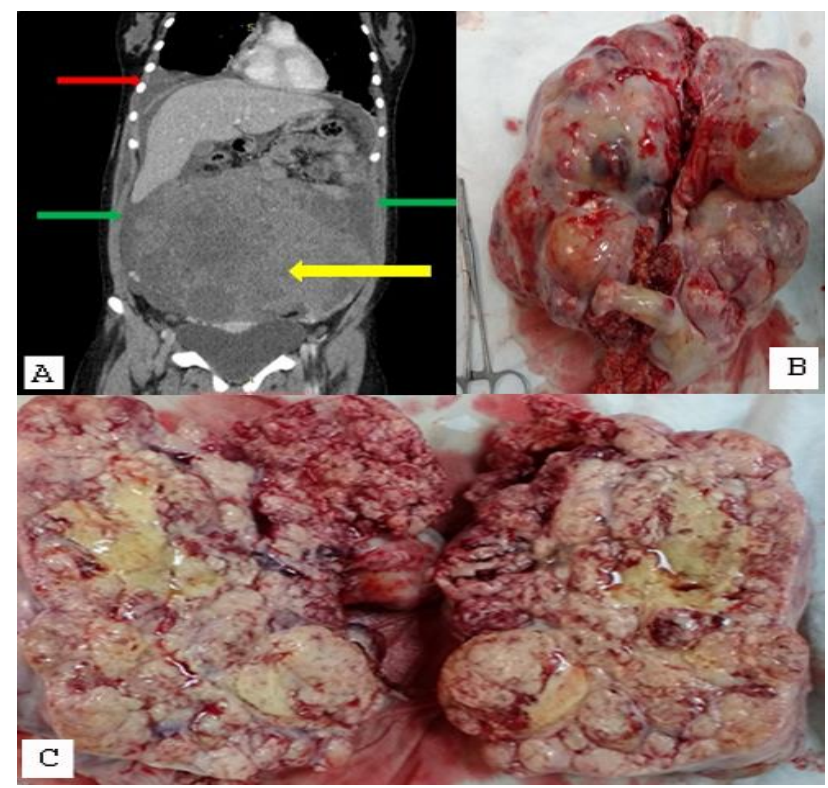

Figure 1: A. CECT scan coronal section [Right sided pleural effusion (red arrow), Huge tumor occupying the abdomen (yellow arrow), Bilateral ascites (green arrows)]; B. Glistening, white- yellow, bosselated mass; C. Cut surface shows whitish, solid and variegated areas of haemorrhage and necrosis.

On inspection of abdomen, there was irregular enlargement with swelling more on the right side. Umbilicus was everted but there were no prominent vessels visible. On palpation, there was a single mass of $25 \times 18 \mathrm{~cm}$ size, reaching beyond the umbilicus, hard, with irregular surface, ill-defined margins and restricted mobility. There was no fluid thrill and on percussion there was dullness over the mass. No bruit was heard over the mass.

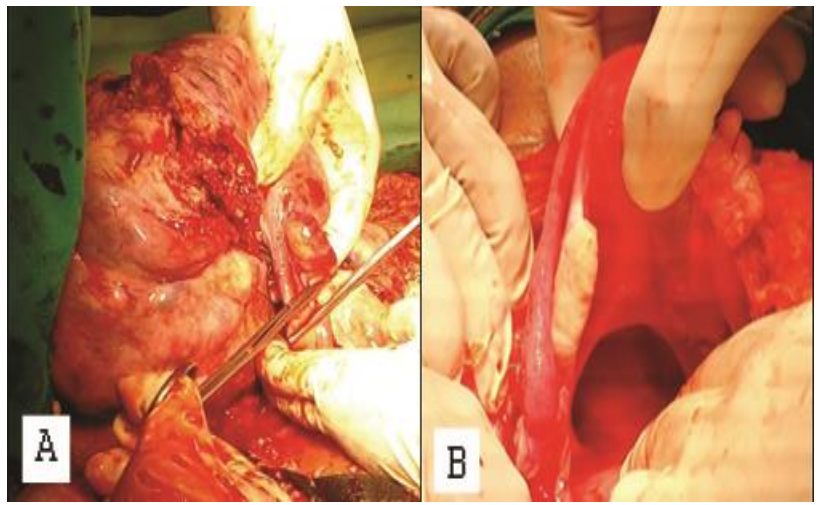

Figure 2: A. The mass being excised during laparotomy; B. On laparotomy, uterus, left ovary and fallopian tube appeared normal.

Her investigations were as follows: hemoglobin- $10 \mathrm{~g} \%$, total leucocyte count- $16,300 / \mathrm{mm} 3$, platelet count- 4.2 $\mathrm{lac} / \mathrm{mm} 3$, serum creatinine- $0.8 \mathrm{mg} \%$, liver function testwithin normal limits. Markers were grossly abnormal: CA-125 - 834.5 U/ml (n- < 35), beta - hCG- 22,167 $\mathrm{mIU} / \mathrm{ml}(\mathrm{n}-<5.3)$, serum AFP- $3923 \mathrm{ng} / \mathrm{ml}(\mathrm{n}-<12)$ and serum LDH- 360mg\% (n- <290).

Chest X-ray- no abnormality. On transabdominal sonography, there was a right sided huge (191 x $176 \mathrm{x}$ $104 \mathrm{~mm}$ ) solid abdomino-pelvic mass with heterogeneous echotexture behind the uterus and extending up to the epigastric region. CT scan revealed one 24 x $20 \times 12 \mathrm{~cm}$ well defined, heterogeneously enhancing hypodense mass extending from the pelvis to the xiphisternum. (Figure 1A). On laparotomy, there was a small amount of straw colored ascitic fluid. There was a huge $20 \times 15 \times 15 \mathrm{~cm}$ glistening, yellow - white, bosselated mass, occupying whole of the abdomen and appearing to be arising from right adnexa (Figure 2A).

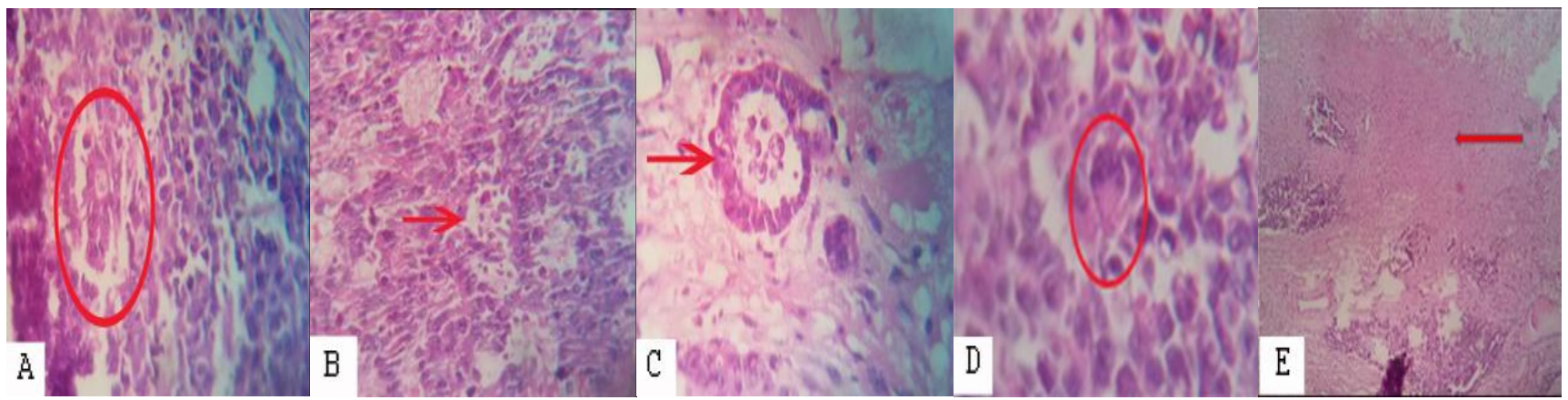

Figure 3: A. Schiller-Duval body (red circle) feature of EST (H\&E, x400); B. Hyaline globules (red arrow) containing AFP (alpha feto protein) globules feature of EST (H\&E, x400); C. Embryoid body like structure feature of embryonal cancer (H\&E, x400); D. Syncytiotrophoblastic giant cell (red circle) in non-gestational choriocarcinoma (H\&E, x400); E. Areas of necrois (red arrow) feature of non-gestational choriocarcinoma $(\mathrm{H} \& \mathrm{E}, \mathbf{x 2 0 0})$. 
Uterus, left ovary and fallopian tube appeared normal (Figure 2B). Intestines, liver and spleen surface and the peritoneum appeared to be normal on inspection and palpation. There was no palpable retroperitoneal LN. Therefore, excision of the mass with right sided unilateral salpingoophrectomy and infracolic omentectomy was done. Surgical stage is IA.

On gross examination, it was a $2.25 \mathrm{~kg}, 16 \times 16 \times 12 \mathrm{~cm}$ solid globular yellowish- white mass. No obvious capsule rupture was seen (Figure 1B). The cut surface of the mass showed whitish, solid and variegated areas of haemorrhage and necrosis. There were yellow cheese like areas and cystic spaces with clear straw colored fluid. (Figure 1C). On microscopic examination, sections showed wide areas of necrosis (Figure 3E), haemorrhage with highly pleomorphic cells in reticular, microcystic, solid sheets and glandular pattern. Cells have pleomorphic, hyperchromatic nuclei and prominent nucleoli. There were few Schiller-Duval bodies and hyaline globules (Figure $3 \mathrm{~A}$ and 3B). Few syncytiotrophoblast like cells were present too (Figure 3D). Few Embryoid body like elements were also seen (Figure 3C). Features were consistent with mixed germ cell tumor- with components of predominantly yolk sac tumor and with elements of non-gestational choriocarcinoma and embryonal carcinoma. No malignant cells were found in ascitic fluid and omental biopsy.

Post-operatively patient was started on chemotherapy containing Bleomycin, Etoposide and Cisplatin for 4 cycles. Patient was followed with USG and serum markers at completion of the 4 cycles and thereafter, at 6 month and 12 month.

\section{DISCUSSION}

Germ cell tumors are classified as Dysgerminoma, Endodermal sinus tumor (Yolk sac tumor), Embryonal carcinoma, Polyembryoma, non-gestational Choriocarcinoma, Teratomas (Immature, Mature, and Monodermal), Mixed and Gonadoblastoma. ${ }^{1}$ Dysgerminoma is the most common malignant germ cell tumor, accounting for about $30 \%$ to $40 \%$ of all ovarian cancers of germ cell origin. ${ }^{2-4}$

Ours is a case of mixed malignant germ cell tumor consisting of predominantly yolk sac tumor with component of embryonal and choriocarcinoma. Mixed malignant germ cell tumors contain 2 or more elements of the lesions described above. The most frequent combination is dysgerminoma with an EST/YST accounting for one-third of the cases. ${ }^{1}$ Other combination include choriocarcinoma and immature teratoma in decreasing order of frequency. Therefore, our case is quite rare. Recently in 2014 a case was reported of mixed germ cell tumor consisting of EST, mature teratoma, embryonal carcinoma, and trophoblastic giant cells. The gross appearance varies according to the individual constituents of the tumor. Immunohistochemistry is a widely used biological technique that helps in the diagnosis and development of new management modalities. ${ }^{5,6}$ Trinh DT et al. described the utility of CD117, CD133, SALL4, OCT4, TCL1 and glypican-3 in malignant germ cell tumors of the ovary. ${ }^{6}$

Yolk sac tumor/ endodermal sinus tumor are derived from primitive yolk sac. Grossly they are soft grayishbrown. Cystic areas are caused by degeneration or necrosis and these lesions are rapidly growing. Microscopically, the characteristic feature is endodermal sinus or Schiller- Duval body. Most YST secrete AFP and rarely alpha-1 antitrypsin. They are highly aggressive but with surgery and combination chemotherapy, the five-year survival with stage 1 tumors and more advanced disease are $92 \%$ and $29 \%$ to $44 \%$ respectively.

Embryonal carcinoma of ovary is extremely rare tumor and is usually present along with other components. Age of patients range from 4 and 28 years. They secrete estrogen, with patient exhibiting symptoms and signs of precocious pseudo puberty or irregular bleeding. They frequently secrete AFP and beta- hCG. The clinical picture is similar to that of EST. Embryonal carcinomas are one of the most malignant cancers arising in the ovary with survival in the first reported series of 15 patients being $39 \%$, with $50 \%$ of stage I patients being disease free at 3.75 to 15 years post-surgery and chemotherapy. ${ }^{8}$

Pure non-gestational choriocarcinamo of the ovary is extremely rare tumor. Most of the patients are younger than 20 years. They secrete hCG and isosexual precocity occurs in about $50 \%$ of patients whose lesions appear before menarche.

In this case, young age of the patient, rapidly growing huge mass in the abdomen with raised levels of AFP and beta-hCG lead to the suspicion of mixed germ cell tumor containing EST, embryonal cancer and choriocarcinoma. Presence of unilateral, huge, yellow, bosselated mass on laparotomy and histopathology confirmed the findings of mixed malignant germ cell tumor. Combination of EST with non-gestational choriocarcinoma and embryonal carcinoma is quite rare with very few reported cases.

All patients except those with FIGO stage 1A require combination chemotherapy. These lesions should be best managed by fertility preserving surgery (i.e. unilateral salpingoopherectomy) followed by 4 cycles of adjuvant combination chemotherapy, preferably BEP (Bleomycin, Etoposide and Cisplatin). More recent data illustrate the improved survival achievable with conservative surgery and combination chemotherapy, with survival figures of $98 \%$ and $94 \%$ for early and advanced stage tumours. ${ }^{9}$ Nishio et al demonstrated that the type of surgical procedure was not an important prognostic factor for patients with malignant germ cell tumors of the ovary at all clinical stages, indicating that conservative, fertility sparing surgery is appropriate as long as 
chemotherapeutic agents are employed. ${ }^{10,11}$ A study by Zanetta et al. confirmed that normal gonadal function and fertility are possible after conservative surgery for ovarian germ cell malignancies, even with adjuvant chemotherapy. ${ }^{12}$

The serum markers if positive initially may become negative during chemotherapy, but this finding may reflect regression of only a particular component of the mixed lesion. The most important prognostic feature is size of the primary tumor and the relative size of the most malignant component. For stage IA lesion smaller than $10 \mathrm{~cm}$, the survival rate is $100 \%$. Tumors composed of less than one- third EST, choriocarcinoma, or grade 3 immature teratoma have excellent prognosis.

In our case majority of the component is yolk sac tumor with elements of embryonal and choriocarcinoma therefore, the prognosis is poor. We have performed unilateral salpingooopherectomy followed by chemotherapy for fertility preservation. Most patients with mixed ovarian germ cell tumors are cured, but a small percentage develop recurrence usually within 24 months of primary diagnosis. Because of the rarity of relapse in this population, there is no standard approach, with treatment strategies extrapolated from clinical experience with testicular cancer patients. ${ }^{13}$

\section{CONCLUSION}

Mixed germ cell tumor (YST/EST, non-gestational choriocarcinoma, embryonal carcinoma) is a very rare tumor and is highly malignant. Careful initial surgery with adequate staging biopsies followed by combination chemotherapy can greatly improve the prognosis of these patients.

Funding: No funding sources Conflict of interest: None declared

Ethical approval: Not required

\section{REFERENCES}

1. Gershenson DM. Update on malignant ovarian germ cell tumors. Cancer. 1993;71(4 Suppl):1581-90.

2. Scully RE, Young RH, Clement PB. Tumors of the ovary, maldeveloped gonads, fallopian tube, and broad ligament. In: Atlas of tumor pathology. Washington, DC: Armed Forces Institute of Pathology. 1998: Fascicle 23,3rd series.

3. Berek JS, Friedlander M, Hacker NF. Epithelial ovarian, fallopian tube and peritoneal cancer. In:
Berek and Hacker's gynecologic oncology. $5^{\text {th }}$ ed. Philadelphia, PA: Lippincott Williams \& Wilkins; 2009:443-508.

4. Kurman RJ, Scardino PT, Waldmann TA, et al. Malignant germ cell tumors of the ovary and testis: an immunohistologic study of 69 cases. Ann Clin Lab Sci. 1979;9:462-66.

5. de Jolinière JB, Ben Ali N, Fadhlaoui A, Dubuisson JB, Guillou L, Sutter A et al. Two case reports of a malignant germ cell tumor of ovary and a granulosa cell tumor: interest of tumoral immunochemistry in the identification and management. Front Oncol 2014;4:97.

6. Trinh DT, Shibata K, Hirosawa T, Umezu T, Mizuno M, Kajiyama $\mathrm{H}$ et al. Diagnostic utility of CD117, CD133, SALL4, OCT4, TCL1 and glypican-3 in malignant germ celltumors of the ovary. J Obstet Gynaecol Res. 2012;38(5):841-8.

7. Kawai M, Kano T, Furuhashi Y, Misawa T, Nakashima N, Hattori S. Prognostic factors in yolk sac tumours of ovary. A clinicopathological analysisof 29 cases. Cancer. 1991;67:184-92.

8. Kurman RJ, Norris HJ. Embryonal carcinoma of the ovary. A clinicopathological entity distinct from endodermal sinus tumour resembling embryonal carcinoma of the adult testis. Cancer. 1976;38:242033.

9. Low JH, Perrin LC, Crandon AJ, Hacker NF. Conservative surgery to preserve ovarian function in patients with malignant ovarian germ cell tumours. A review of 74 cases. Cancer. 2000;89:391-8.

10. Nishio S, Ushijima K, Fukui A, Fujiyoshi N, Kawano K, Komai K et al. Fertility-preserving treatment for patients with malignant germ cell tumors of the ovary. J Obstet Gynaecol Res. 2006;32:416.

11. Tewari K, Cappuccini F, Disaia P, Berman ML, Manetta A, Kohler MF. Malignant germ cell tumors of the ovary. Obstet Gynecol. 2000;95:128.

12. Zanetta G, Bonazzi C, Cantu M, Bini S, Locatelli A, Bratina $\mathrm{G}$ et al. Survival and reproductive function after treatment of malignant germ cell ovarian tumors. J Clin Oncol. 2001;19(4):1015-20.

13. Gershenson DM. Management of ovarian germ cell tumors. J Clin Oncol. 2007;25:2938.

Cite this article as: Vali FS, Kyal A, Chaudhary PI, Das S, Mukherjee A, Mukhopadhyay P. A rare case of mixed germ cell tumor in a teenage girl: A case report. Int J Reprod Contracept Obstet Gynecol 2017;6:2663-6. 